\title{
PEMANFAATAN ANGLE FOTOGRAFI PADA FOTO DOKUMENTASI
}

\author{
M.Ifran Sanni ${ }^{1}$ \\ Yudi Dian ${ }^{2}$ \\ Ramdhan $^{3}$ \\ Alumni Magister STIM LPMI Jakarta ${ }^{1}$, STMIK Raharja Jurusan Teknik Informatika ${ }^{2,3}$ \\ Jl. Rawamangun Muka, Jakartal, Jl. Jendral Sudirman No. 40, Modernland, Tangerang ${ }^{2,3}$ \\ Email: ifran@raharja.info ${ }^{l)}$ yudi.dianpratama@ raharja.info ${ }^{2}$ ramadhan@ raharja.info
}

\begin{abstract}
ABSTRAK
Fotografi sejak awal kemunculannya sudah menjadi bagian tak terpisahkan dari kehidpuan manusia. Banyak sekali momen indah yang berhasil diabadikan oleh kegiatan fotografi ini. Merekam berbagai aktifitas manusia dimanapun berada dan membekukannya dalam sebuah karya foto menjadikan kegiatan ini sangat menarik untuk dilakukan. Sebuah karya foto mampu mengungkapkan perasaan kita, hubungan antar manusia hingga menampilkan keindahaan ciptaan Tuhan. Fotografi adalah sebuah seni, oleh karena itu untuk mendapatkan hasil karya seni maka kita berkesempatan juga mempelajari hal-hal berkaitan dengan teknik fotografi yang baik. Ada kaidah-kaidah yang terkandung dalam seni fotografi itu sendiri. Dengan mempelajari teknik fotografi serta sering mempraktekannya, kita akan semakin memahami estetika dari sebuah foto agar menghasilkan foto yang indah dan menarik . selain itu kita semakin terlatih menyampaikan suatu pesan lewat media foto kepada siapapun yang melihatnya.
\end{abstract}

Kata kunci: Fotografi, Multimedia.

\begin{abstract}
Since its inception photography has become on indispensable part of human life. There are lpt of beautiful momentshas successfully captured by this photograph activity. Capturing human activities whereher located and freeze in a photpgraphic word made this event veri interesting to dol a photograph is able to express our fellings, human relationships to show the beauty of divine creation. Photography techniques there are rules contained in the art of photography it self. Learning by techniques of photography and often practice, we able understand the aesthetics of a photography to draw a great picture and interesting. In addition, we will be trained to convey a message through media photograph to everyone.
\end{abstract}

Keywords: Photography, Multimedia

\section{PENDAHULUAN}

Pada awalnya fotografi tercipta didasari dari melukis atau menggambar dengan bantuan cahaya dari kata Yunani, Phos yang berarti cahaya dan Graphein yang berarti menulis atau menggambar. Prinsip dasar fotografi sudah ada sejak zaman Aristoteles yaitu berupa reaksi gelombang cahaya yang diproyeksikan melalui celah kecil. Fotografi merupakan alat rekam visual yang membutuhkan cahaya dan momentum. Cahaya disini untuk menimbulkan emulsi film yang ditangkap oleh kamera dan momentumnya adalah sesuatu obyek yang terbekukan dalam proses pemotretan. Munculnya fotografi merupakan hasil dari dua penemuan yaitu: yang pertama berasal dari bidang ilmu alam yang menghasilkan kamera dengan apa yang disebut sebagai camera obscura (camera = kamar dan obscura = gelap), dan yang kedua berasal dari bidang kimia yang menghasilkan film1. Lahirnya fotografi tentunya tidak lepas juga dari tokoh-tokoh yang secara 
fenomenal telah melakukan berbagai jenis eksperimen, seperti : Thomas Wedgwood, Niepce, Daguerre, Talbot dan George Eastman. Tokoh-tokoh tersebut sangat berjasa bagi perkembangan fotografi dari yang sederhana hingga menjadi fotografi modern Kehadiran fotografi pada masa lalu menimbulkan pro dan kontra di kalangan seniman karena fotografi lahir sebagai alat rekam yang dapat merekam obyek nyata menjadi gambar yang sangat mirip dengan aslinya. Penemuan revolusioner tersebut sempat mengundang kecemburuan di kalangan pelukis pada masa tersebut. Perjuangan para praktisi foto sangat berat pada masa era Victorian, ketika sejarah awal fotografi baru saja di mulai sekitar awal tahun 1830-an banyak para fotografer menganggap fotografi sebagai bentuk seni yang baru sebuah bentuk lain dari lukisan. Seperti apa yang diproklamirkan oleh Peter Henri Emerson bahwa seni foto yang sesungguhnya hanya bisa dicapai bila potensi kamera yang sesungguhnya dikembangkan, bukan sebagai imitator lukisan namun potensi tersebut adalah kemampuan merekam realitas apa adanya, tidak sempurna 3

tetapi riil. Dari perjuangan yang dilakukan oleh banyak seniman foto pada masa tersebut, lambat laun fotografi mulai diterima keberadaannya baik oleh para seniman maupun masyarakat sebagai salah satu cabang seni yang baru dimana fotografi memiliki daya cipta yang sungguh mengagumkan dan penuh rangsangan.

Kebanyakan fotografer mengambil gambar potret dari beberapa titik. Anda mungkin tidak berpikir seperti itu, Anda mungkin hanya berpikir bahwa hal itu sebagai foto liburan, foto dokumentasi atau foto keluarga, akan tapi kalau ada objek orang di dalamnya, hal itu juga bisa disebut portrait photography. Mengambil gambar dengan objek manusia adalah merupakan sebuah hal yang sangat sulit dan dibutuhkan banyak sekali trik khusus, dari mulai mencari ide tentang apa yang sedang mereka kerjakan dan tidak tampak seperti akan difoto, dan bagaimana cara agar orang tersebut terlihat natural di kamera.

\section{LITERATURE REVIEW}

1. Teknologi Motion Capture Untuk Pengenalan Teknik Dasar Sepak Bola adalah salah satu jurnal yang dibuat oleh Novita Wulandari sebagai mahasiswa teknik informatika, universitas nasional jakarta. Penelitian ini menjelaskan tentang kurangnya teknologi dengan capcure dengan cara teknik dasar sepak bola $2013^{[4]}$.

2. Penerapan Camera Angle dalam Karya Audio Visual adalah salah satu jurnal yang dibuat oleh teguh imanto ilmu komunikasi broadcasting universitas esa unggul jakarta $2012^{[1]}$.

3. Analisis film dalam mihrab cinta menuntut perspektif dakwah islam adalah salah satu skripsi yang dibuat oleh khafidhoh fakultas dakwah institut agama islam negeri walisongo semarang. Penelitian ini menjelaskan tentang kurangnya dakwah islam dalam cara membuat filam mirab cinta $2012^{[2]}$.

4. Perancangan dan pembuatan video klip musik wanita khayalan dari randy dengan teknik match movie objek 3D adalah satu skripsi yang dibuat oleh Muhammad Aswin Zulkarmain dari sekolah tinggi manajemen informatika dan komputer AMIKOM Yogyakarta. Penelitian ini menjelaskan tentang kurangnya tata cara pembuatan video klip musik wanita khayalan $2013^{[5]}$.

5. Analisis Sudut Pandang Kamera adalah salah satu jurnal yang dibuat oleh Listia Natadjaja, Dedy Setyawan, Hanny Limantara fakultas seni dan desain, universitas kristen petra surabaya 2014.. Penelitian ini menjelaskan tentang study kasus salah satu film the $\operatorname{ring} \mathrm{I}^{[3]}$. 
Dari ke lima Literature Review diatas saya mengambil kesimpulan dengan judul Pemanfaatan Angle Fotografi Pada Foto Dokumentasi yang membuat tentang angle kamera dalam pengambilan gambar pembuat bernama M. Ifran, Yudi dian, Ramdhan, Perguruan Tinggi Raharja. Tahun 2016

\section{Bird Eye}

Sudut pengambilan gambar ini, posisi objek dibawah / lebih rendah dari kita berdiri. Biasanya sudut pengmbilan gambar ini digunakan untuk menunjukkan apa yang sedang dilakukan objek (HI), elemen apa saja yang ada disekitar objek, dan pemberian kesan perbandingan antara overview (keseluruhan) lingkungan dengan POI (Point Of Interest).

\section{High Angle}

Pandangan tinggi. artinya, pemotret berada pada posisi yang lebih tinggi dari objek foto.

\section{Eye Level}

Sudut pengembilan gambar yang dimana objek dan kamera sejajar / sama seperti mata memandang. Biasanya digunakan untuk menghasilkan kesan menyeluruh dan merata terhadap background sebuah objek, menonjolkan sisi ekspresif dari sebuah objek (HI), dan biasanya sudut pemotretan ini juga dimaksudkan untuk memposisikan kamera sejajar dengan mata objek yang lebih rendah dari pada kita missal, anak - anak.

\section{Low Angle}

Pemotretan dilakukan dari bawah.

Sudut pemotretan yang dimana objek lebih tinggi dari posisi kamera. Sudut pengembilan gambar ini digunakan untuk memotret arsitektur sebuah bagunan agar terkesan kokoh, megah dan menjulang. Namu, tidak menutup kemungkinan dapat pula digunakan untuk pemotretan model agar terkesan elegan dan anggun.

\section{Frog Eye}

Sudut penglihatan sebatas mata katak. Pada posisi ini kamera berada di dasar bawah, hampir sejajar dengan tanah dan tidak dihadapkan ke atas. Biasanya memotret seperti ini dilakukan dalam peperangan dan untuk memotret flora dan fauna.

\section{Over Shoulder}

Pengambilan gambar dari belakang bahu salah satu pemain. Teknik ini di gunakan untuk menunjukan expresi lawan bicara saat sedang berdialog.

\section{Extreme Close Up}

Pengambilan gambar yang sangat dekat sekali dengan objek, sehingga detil objek seperti pori-pori kulit akan jelas terlihat.

\section{Head Shot}

Pengambilan gambar sebatas kepala hingga dagu.

\section{Close Up}

Pengambilan gambar dari atas kepala hingga bahu.

\section{Medium Close Up}

Pengambilan gambar dari atas kepala hingga dada.

\section{Mid Shot (setengah badan)}

Pengambilan gambar dari atas kepala hingga pinggang.

\section{Medium Shot (Tiga perempat badan)}

Pengambilan gambar dari atas kepala hingga lutut.

\section{Full Shot (Seluruh Badan)}

Pengambilan gambar dari atas kepala hingga kaki.

\section{Long Shot}

Pengambilan gambar dengan memberikan porsi background atau foreground lebih banyak sehinnga objek terlihat kecil atau jauh. 
Beberapa jenis komposisi dari segi banyaknya manusia sebagai objek yang difoto adalah sebagai berikut :

\section{a. One Shot}

Pengambilan gambar untuk satu orang sebagai objek.

\section{b. Two Shot}

Pengambilan gambar untuk dua orang sebagai objek.

\section{c. Three Shot}

Pengambilan gambar untuk tiga orang sebagai objek.

\section{d. Group Shot}

Pengambilan gambar untuk sekelompok orang sebagai objek.

\section{Angle 1}

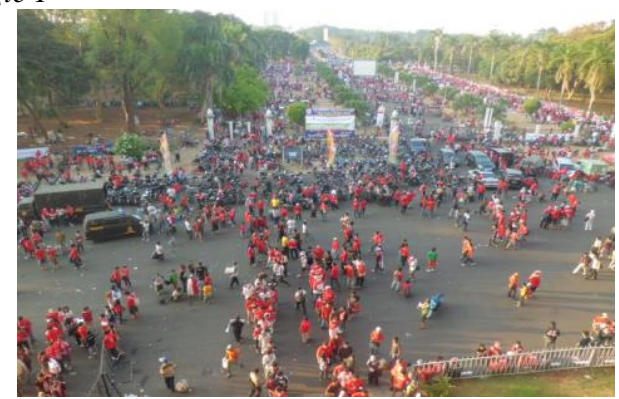

Gambar 1 . Eye Bird

Angle 2

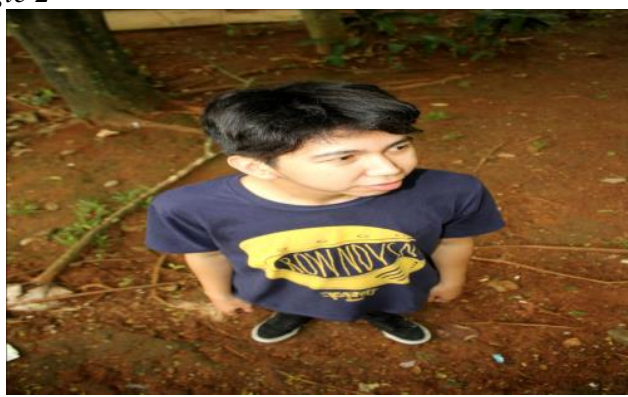

Gambar 2 . High Angle

Angle 3

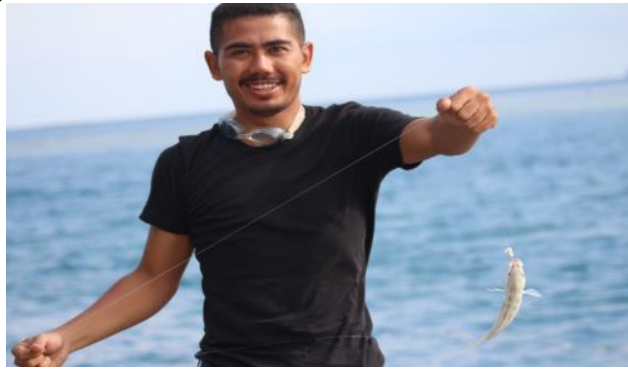

Gambar 3 . Eye Level
Angle 4

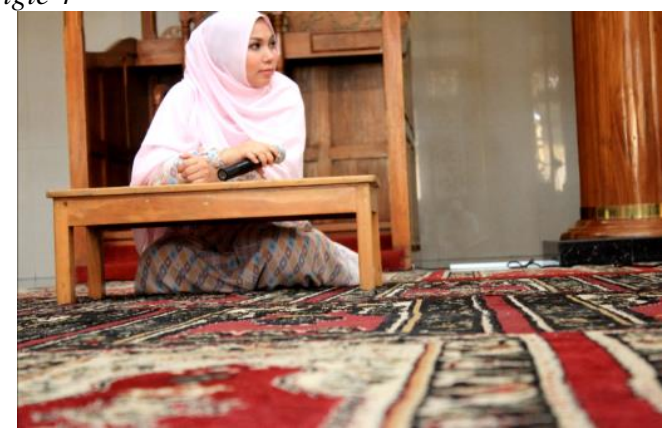

Gambar 4 . Low Angle

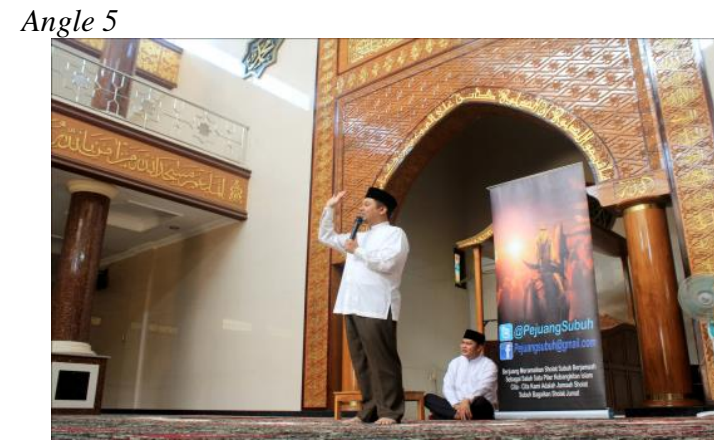

Gambar 5 . Frog Eye

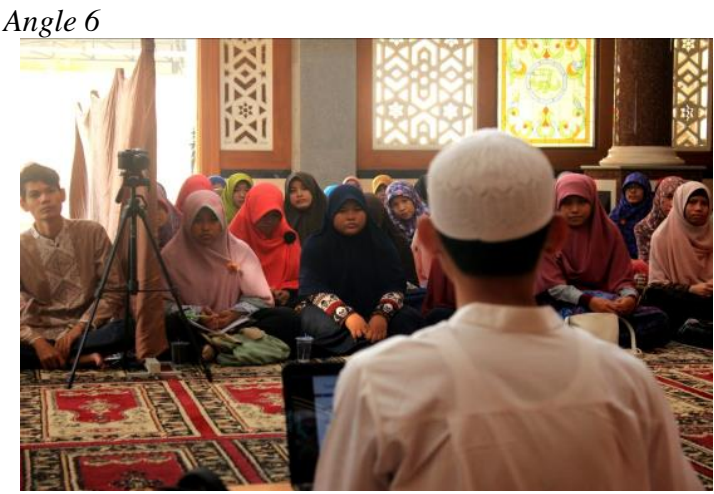

Gambar 6 . Over Shoulder

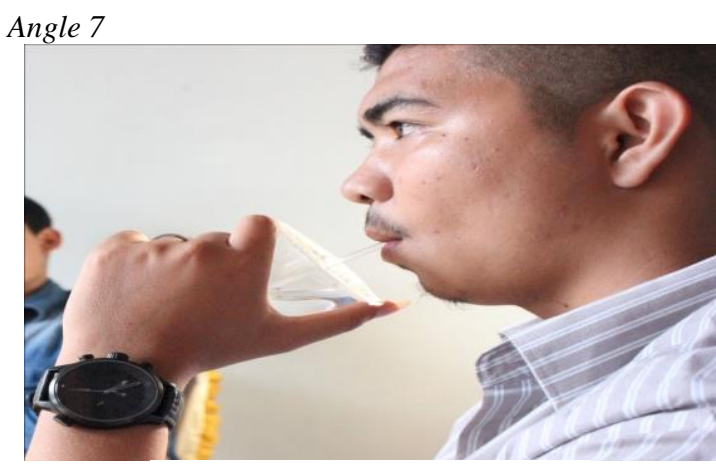

Gambar 7 . Extream Close Up 


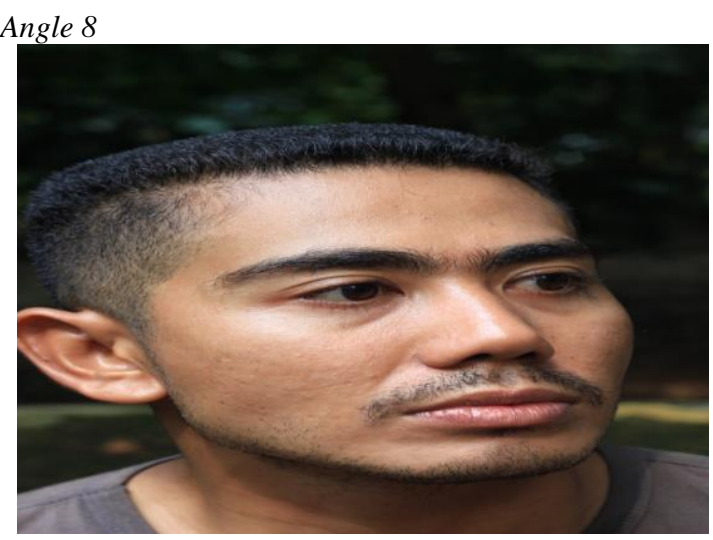

Gambar 8 . Head Shot

Angle 9

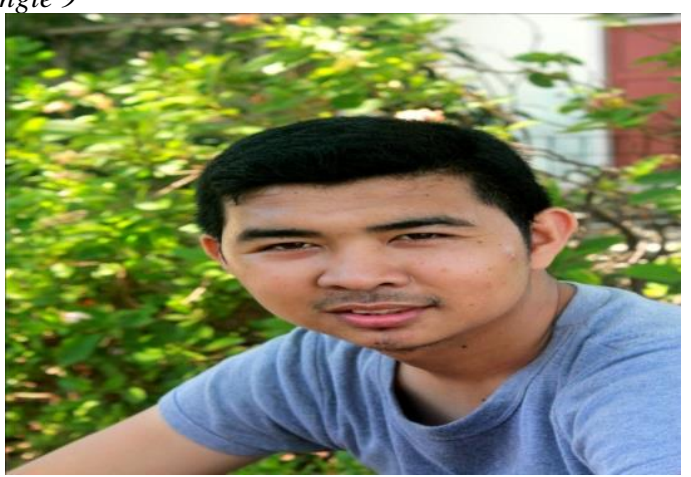

Gambar 9 . Close Up

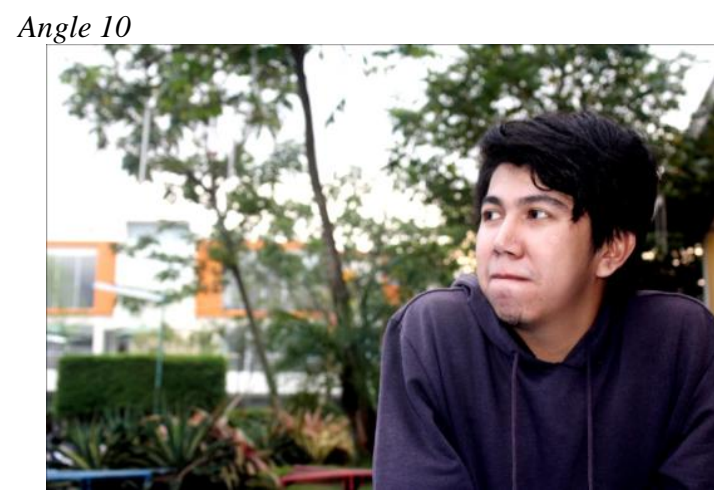

Gambar 10 . Medium Close Up

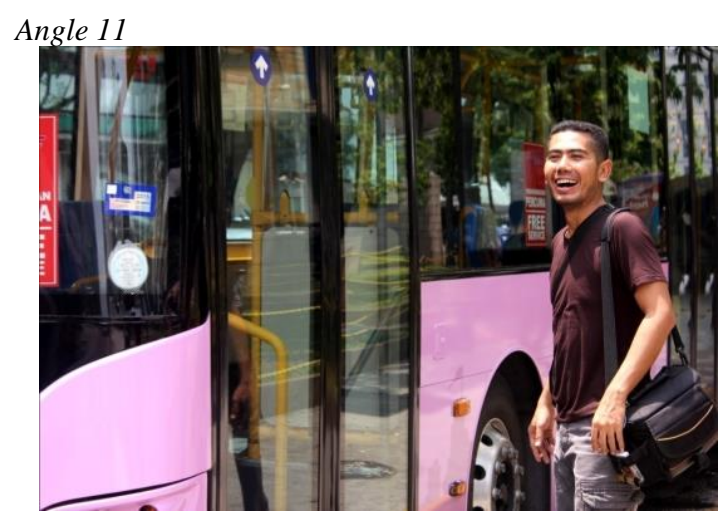

Gambar 11 . Mid Shot
Angle 12

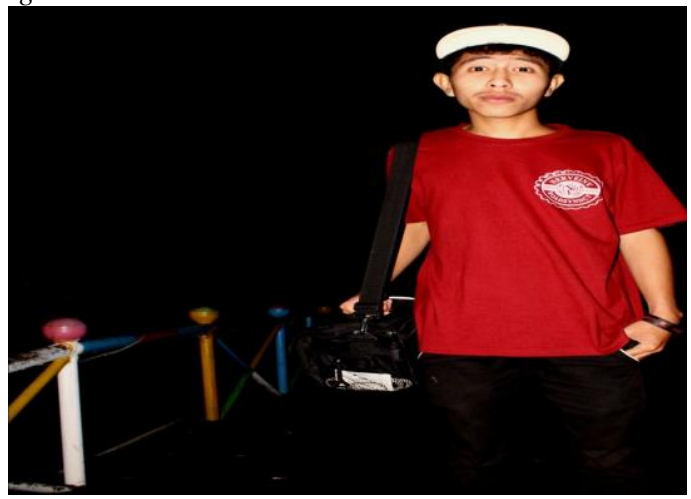

Gambar 12 . Medium Shot

Angle 13

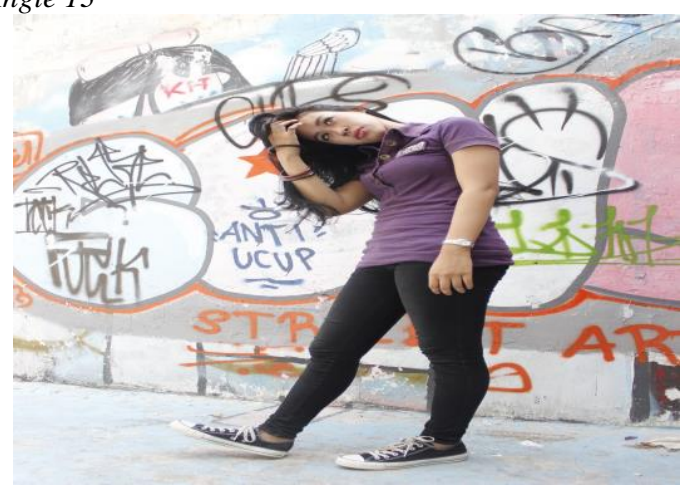

Gambar 13. Full Sho

Angle 14

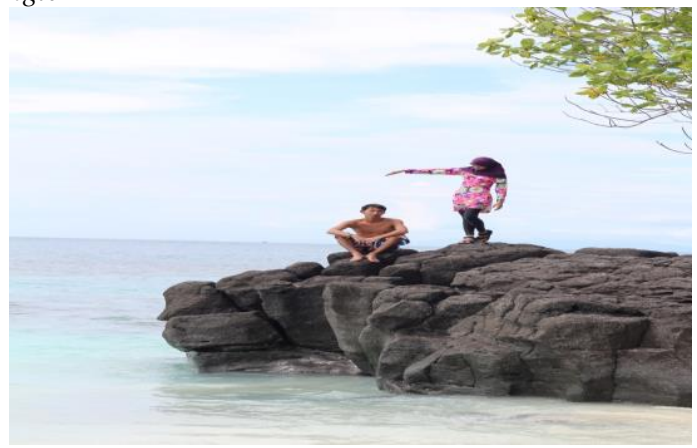

Gambar 14. Long Shot

Angle 15

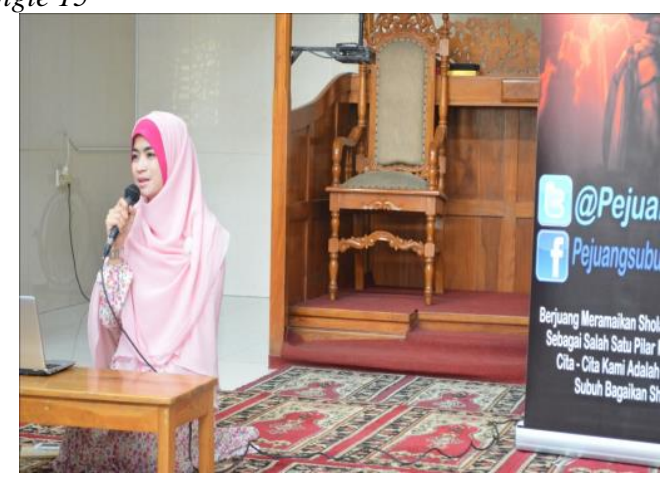

Gambar 15. One Shot 


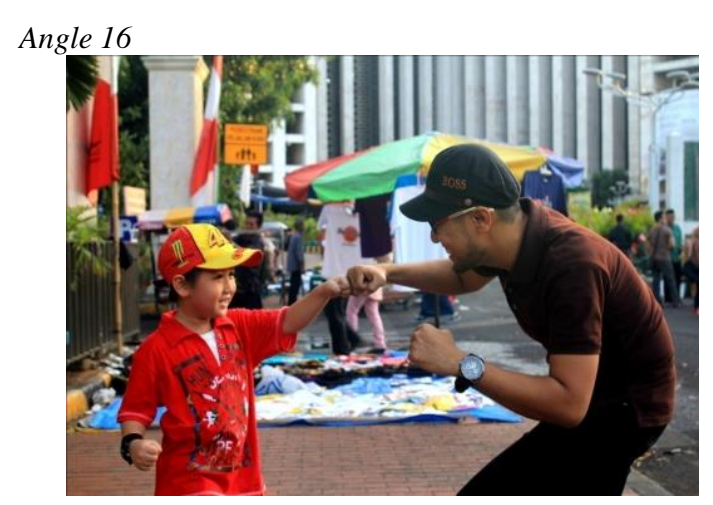

Gambar 15. Two Shot

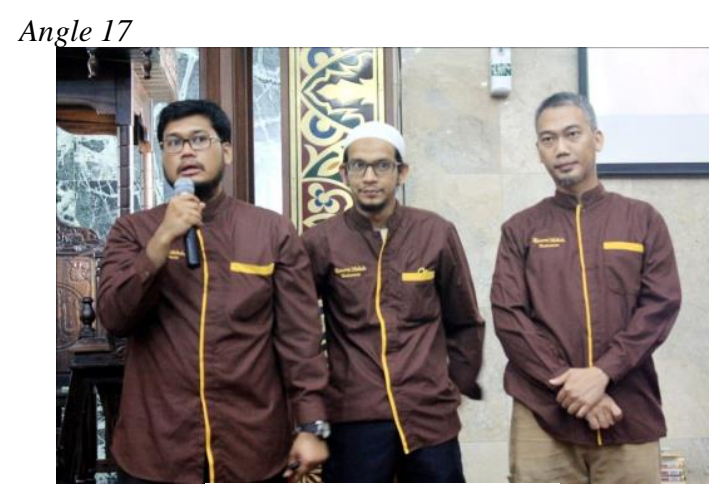

Gambar 15. Three Shot

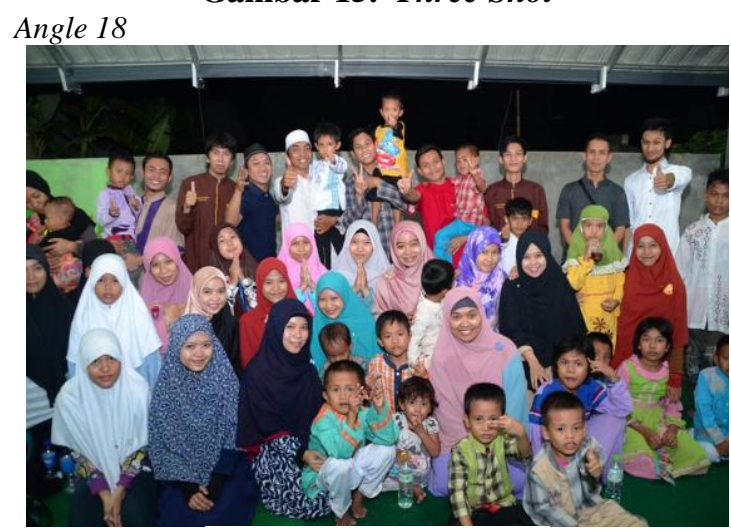

Gambar 15. Grup Shot

\section{Klasifikasi Fotografi}

Sebenarnya

pengklasifikasian fotografi ini sulit dan bersifat subjektif, namun secara umum dapat dibagai atas 5 bidang yaitu:

1. Lokasi dan Jenis Objek: Urban, Travel, Nature, Wild Life, Under Water Photography

2. Aktivitas Manusia: Wedding, Event, Sport Photography

3. Ilmu Pengetahuan (Science): Forensic, Science, Medical Photography

4. Konsep: Art, Documentary, Advertising Photography
5. Teknik/Peralatan Fotografi: Wide, Macro, Aerial Photography

Adapun faktor-faktor yang menentukan kualitas hasil foto adalah:

1. Kondisi Objek

2. Pencahayaan (Exposure)

3. Warna

4. Fokus/Ketajaman (Sharpness)

5. Komposisi

6. Sudut Pandang (Viewing Angel)

\section{Kondisi Objek}

Bisa dikatakan kondisi objek memiliki peranan penting dalam suatu foto yang bagus. Apakah ekspresi dari objek atau objek yang merupakan peristiwa yang unik atau jarang terjadi.

\section{Pencahayaan (Exposure)}

Masalah cahaya ini, tergantung tujuan foto yang diambil, bisa saja foto yang agak gelap atau terlalu terang malah bagus. Tapi secara umum pencahayaan yang bagus itu harus pas.

\section{Warna}

Pengetahuan mengenai warna cukup penting juga dalam dunia fotografi. Seorang graphic designer, ataufashion designer paham benar memainkan warna. Colourlovers, di situs ini bisa belajar dan memahami warna dengan baik.

\section{Fokus/Ketajaman (sharpness)}

Penggunaan manual fokus butuh latihan yang sering, untuk pemula make autofokus saja dulu.

\section{Komposisi}

Prinsip dasarnya adalah seimbang. Perhatikan orientasi yang cocok, portrait atau landscape, biasanya panorama atau objek yang jauh cocok menggunakan landscape, sedangkan objek yang vertikal cocok 
menggunakan portrait. Teknik komposisi lain diantaranya adalah Framing, Geometric dan Freedom

Prinsip Rule of Third sangat membantu untuk mendapatkan komposisi yang bagus. Dimana POI atau objek utama diposisikan di bahagian sepertiga bidang foto.

\section{Sudut Pandang (viewing angel)}

Yang ini sangat dipengaruhi oleh sense seni si fotografer, dari sudut mana pengambilan foto yang menarik dan "menjelaskan" objek. Kalau mahir memainkan viewing

angel dan komposisi, nanti bisa jadi Director of Photography.

Teknik Fotografi

Adapun cara-cara 5 teknik fotografi menurut eocommunity, yaitu:

1. Depth of field (ruang tajam)

Hal-hal yang mempengaruhi ruang tajam:

-Jarak pemotretan (jauh=luas, dekat=sempit)

-Bukaan diafragma (kecil=luas, besar=sempit)

-Jarak fokus lensa /focal length (tele=sempit, wide=luas, normal=bisa diatur).

\section{Panning}

-Panning adalah salah satu cara untuk memberikan kesan gerak pada foto.

-Ketika melakukan panning, anda harus mengikuti objek selama membidik.

-Hasil foto menjadikan objek menjadi relatif tajam dibandingkan dengan backgroundnya yang hampir sepenuhnya blur.

-Untuk mendapatkan foto panning secara maksimal; dengan speed rendah (8-60), dan pakailah tripod (kaki tiga).

3. Slow \& Stop action

-Slow action : salah satu teknik fotografi yang bertujuan memperlihatkan/menangkap gerakan objek. Biasanya digunakan kecepatan rendah, antara 1/30 sampai 1 detik

-Stop action : kebalikan dari slow, yaitu teknik fotografi untuk bertujuan membekukan gerak objek. Biasanya digunakan kecepatan tinggi, antara 1/125 sampai 1/4000 atau lebih.

\section{Zooming}

-Zooming adalah teknik foto untuk memberikan kesan gerak dengan mengubah panjang fokus lensa.

-Perubahan panjang fokus hanya dapat dilakukan dengan lensa zoom.

-Untuk mendapatkan kesan gerak, anda harus menggunakan kecepatan rana tidak lebih dari 1/30 detik.

-Untuk mendapatkan foto zooming secara maksimal, pakailah tripod (kaki tiga).

\section{Bulb}

-Kecepatan rana dapat diatur sesuai dengan waktu yang kita inginkan.

-Teknik ini dilakukan dengan menahan tombol pelepas rana dengan lebih lama.

-Untuk mendapatkan hasil foto bulb secara maksimal, dapat digunakan kabel release dan tripod.

-Misal, kita mempergunakan kecepatan 30 detik sampai habis waktu perekaman cahaya.

\section{KESIMPULAN}

Media Visual sebagai media fotografi yang dikemas dalam bentuk gambar sangat di perlukan masyarakat yang bertujuan meningkatkan suatu angle kamera yang baik pada saat pengambilan gambar. Mempelajari sebuah media visual harus memperhatikan faktor-faktor yang berhubungan dengan angle kamera yang bersangkutan dalam hal ini penulis menyusuaikan, mulai dari pembuatan angle kamera, isi pesan dan penutup. Hal ini bertujuan untuk memperkuat masyarakat mengetahui cara pengambilan visual dalam mempelajarinya dan menginformasikan cara pengambilan gambar. Pembuatan 
sebuah media visual yang baik dan dapat memenuhi kebutuhan masyarakat yaitu dengan membuat sebuah visual yang berisikan angle kamera yang baik agar hasil visual tersebut bterlihat baik, yang berisikan dari beberapa visual yang berisi gambar tampak lebih menarik.

\section{SARAN}

Saran dari saya, menjadi seorang fotografer harus mempunyai jiwa kreativitas, pantang menyerah, selalu sabar, cekatan . Menjadi seorang fotografer itu penuh proses, jadi jika kalian ingin menjadi seorang fotografer maka kalian harus benar-benar memahami tentang fotografi sehingga kalian mampu menghasilkan foto yang lebih baik dalam berbagai kondisi pemotretan.

\section{DAFTAR PUSTAKA}

[1] Imanto teguh, 2012, Penerapan Camera Angle dalam Karya Audio Visual, ilmu komunikasi broadcasting universitas esa unggul jakarta.

[2] Khafidhoh, 2012, Analisis film dalam mihrab cinta menuntut perspektif dakwah islam, fakultas dakwah institut agama islam negeri walisongo semarang.

[3] Limantara, Hanny. Setyawan, Dedy Listia Natadjaja, 2014, Analisis Sudut Pandang Kamera, fakultas seni dan desain, universitas kristen petra Surabaya.

[4] Wulandari, Novita, 2013, Teknologi Motion Capture Untuk Pengenalan Teknik Dasar Sepak Bola, teknik informatika, universitas nasional Jakarta.

[5] Zulkarmain, Aswin, Muhammad.

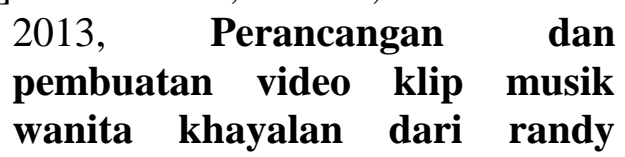

dengan teknik match movie objek 3D, sekolah tinggi manajemen informatika dan komputer AMIKOM Yogyakarta. 